\title{
FROM CREATIVE THINKING TECHNIQUES TO INNOVATIVE DESIGN SOLUTIONS - THE EDUCATORS' PERSPECTIVE
}

\author{
Joanna Maria Kowalewska, ${ }^{1}$ Maria Jolanta Soltysik ${ }^{2}$
}

\begin{abstract}
For every designer, it is crucial to be creative. But generating new, innovative ideas tends to be a difficult task. Nevertheless, some technique can be used to improve the quality of the designing process. Getting knowledge about such tools can be of much value for all future architects and engineers. This article presents an original academic course, which was inaugurated in 2015 at the Faculty of Architecture in Gdańsk University of Technology and organized for the first year students of Spatial Planning. The course was repeated in 2016 and is being currently led in 2017. The title of the course was 'Garden Cities and the Gardens in the Cities. A Course with Elements of Training Creativity'. The aim of the course was to encourage the participants to develop their creativity by introducing creative thinking techniques and thus to facilitate their projects. Among the recommended creative thinking techniques were mainly the ones presented in the 'Odyssey of the Mind' educational program, including such techniques as the 'Mind Map,' the 'Brainstorm' and the 'Superheroes.' Moreover, during the study, participants had a chance to improve their team working skills. The practical usage of the introduced innovative methods was to be tested on issues concerning green environmental projects in urban areas. At the end of the course, most of the participants declared, in the final students' questionnaires, to use the recommended techniques in future, and that they strongly appreciated all that they had learned during the study.
\end{abstract}

UDC Classification: 37:[71+73] ; DOI: http://dx.doi.org/10.12955/cbup.v5.1005

Keywords: creative thinking, problem-solving techniques, academic course, innovative designs, team working skills

\section{Introduction}

In this article, we present a structure and basic tasks of a new original academic course, which was introduced at the Faculty of Architecture in Gdańsk University of Technology $(2015,2016,2017)$. We describe the main parts of the course in detail, which were: theoretical background lectures, creative 'warm-up' activities and problem-solving techniques. At the same time, we paid attention to another basic aim of the course, which was the development of team working skills of the participants. In the last part of the article, we present the process of evaluation of the students' work and the final results of the students' questionnaires.

\section{Traditional and non-traditional way of creating projects}

Traditionally, at the beginning of the creation process, a designer usually sits over a blank sheet of paper and tries to find an idea for the project. More often than not it is quite difficult to get one. For many reasons, one can be 'blocked' and needs help to proceed with his work. Therefore, the architects and designers should know that there are several specific techniques to facilitate the designing process. These techniques give us a tool - a detailed instruction what actions to undertake in order to generate many creative ideas for our project. However, the question is: how to teach the future designers about the non-traditional, more innovative ways of design? How to teach them 'the problem-solving techniques' and 'creative thinking'?

\section{Innovative course for students}

The above questions were the primary drivers for introducing a new academic course for the first year students of Spatial Planning at the Faculty of Architecture in the Gdańsk University of Technology in the year 2015. The title of the course was 'Garden Cities and the Gardens in the Cities. A Course with Elements of Training Creativity'. The 15-hour course consisted of seven meetings, six of which were divided into three parts: a theoretical background lecture, creative 'warm-up' activities and implementation of problem-solving tools and techniques. The course ended with a final presentation of the project (at the $7^{\text {th }}$ meeting), which was entitled 'The Fantastic Innovative Green City.' Every group of students had to do one such presentation, which needed to contain five obligatory elements: (1) A keynote-slogan of the city; (2) An original architectural idea for a Vertical Farm; (3) An unusual building/structure covered with a green roof; (4) One defined social or spatial problem to be solved by citizens; and (5) At least one other green or ecological solution created by the group.

\footnotetext{
${ }^{1}$ Faculty of Architecture, Gdańsk University of Technology, joanna.kowalewska@pg.edu.pl

${ }^{2}$ Faculty of Architecture, Gdańsk University of Technology, mjsol@wp.pl
} 
Some parts of the course were inspired by the famous worldwide program - 'Odyssey of the Mind' (Kowalewska, 2016). It is an international educational project, introduced in over 25 countries. It promotes a creative, problem-solving competition, that was developed and started in 1970's at Rowan University in New Jersey in the USA (Creative Competitions Inc., 2017). In that competition, teams of up to 7 members, in four age divisions (from primary school to university students) compete in two basic categories - long-term problem-solving presentation and spontaneous problem-solving presentation. The long-term problem-solving presentation is an eight minute public performance on a given topic, prepared by the team before the competition; whereas the spontaneous problem-solving presentation is a short answer to the task, given to the team at the day of competition to be solved right away in a few minutes (Odyssey of the Mind Polska, 2017). One of the authors of this article has been a team member of that program and since 2004 has been a volunteer for Polish part of the 'Odyssey of the Mind.' Therefore, using this experience in her educational practice seemed to be a natural consequence and resulted in the organization of the training creativity course at the Faculty of Architecture in Gdańsk in 2015.

The first part of the class: a theoretical background lecture

At the beginning of every meeting during the course, the teacher was presenting a theoretical background of the subject. Since the main theme was 'Garden Cities and the Gardens in the Cities,' every lecture reflected the different aspects concerning the most important 'green' solutions for an urban space in modern history. Among those solutions were: (1) the idea of Howards' Garden Cities of Tomorrow; (2) the concept of green roofs; (3) the modern projects of vertical gardens; (4) the contemporary idea of vertical farms; and (5) the new concept of a social farm. There were two goals in those lectures. The first was to deliver a basic knowledge about some significant historical and contemporary solutions for green urban areas, and the second was to inspire innovative ideas as a good continuation of the former creativity - not just a repetition.

The second part of the class: creative 'warm-up' activities

The second part of each class were short 'warm-up' activities, stimulating the participants' way of thinking. In order to prepare students for creative work during the further part of the meeting the lecturer gave them a simple task, involving invention and innovation. The task could be connected with a sort of design, drama or artistic activities, performed either in a team or individually. At the same time the teacher encouraged participants to look at the problem from a few different perspectives, preferably quite unusual ones. Some of the tasks could be inspired by the spontaneous part of the 'Odyssey of the Mind' educational program and could introduce a kind of competition between the groups of students. For example, during the 2016 year course, the chosen taskcompetition was 'who would build more bridges connecting two tables in a limited time and using limited materials.' After that competition, the winner group was presented with a catalog of ecological solutions in urban areas. Figure 1 presents a photo of one of the groups solving this task.

The third part of the class: the problem-solving techniques

The last part of every class in the course was the introduction of so called problem-solving techniques. Students could learn how to use this tool to solve their designing problems. For example - to make the final design of 'The Innovative Fantastic Green City' each group of students was asked to generate at least 60 ideas, using for it all of the five recommended problem-solving techniques. Those techniques were: the 'Mind Map' technique, the 'Brainstorm' technique, the 'Problem Reversal' technique, the 'Superposition' technique and the 'Superheroes' technique. They are today the most popular thinking techniques during various kind of workshops.

The 'Mind Map' technique, in its contemporary form and under this name, is known since the 1970s when it was popularized by Tony Buzan. According to Buzan (2005), it is a graphic technique used to unlock the capability of the brain to develop creativity in solving problems. To use this tool one has to write a keyword in the center of the sheet of paper, and then, around the keyword, a few associations and memories connected with it. The next step is to write other associations to the ones already noted, creating kind of a tree or a map. Those notes could be in the form of graphic images or simple words, drawn or written in different colors. Part of the process of the 'Mind Map' creation is shown in Figure 2. 


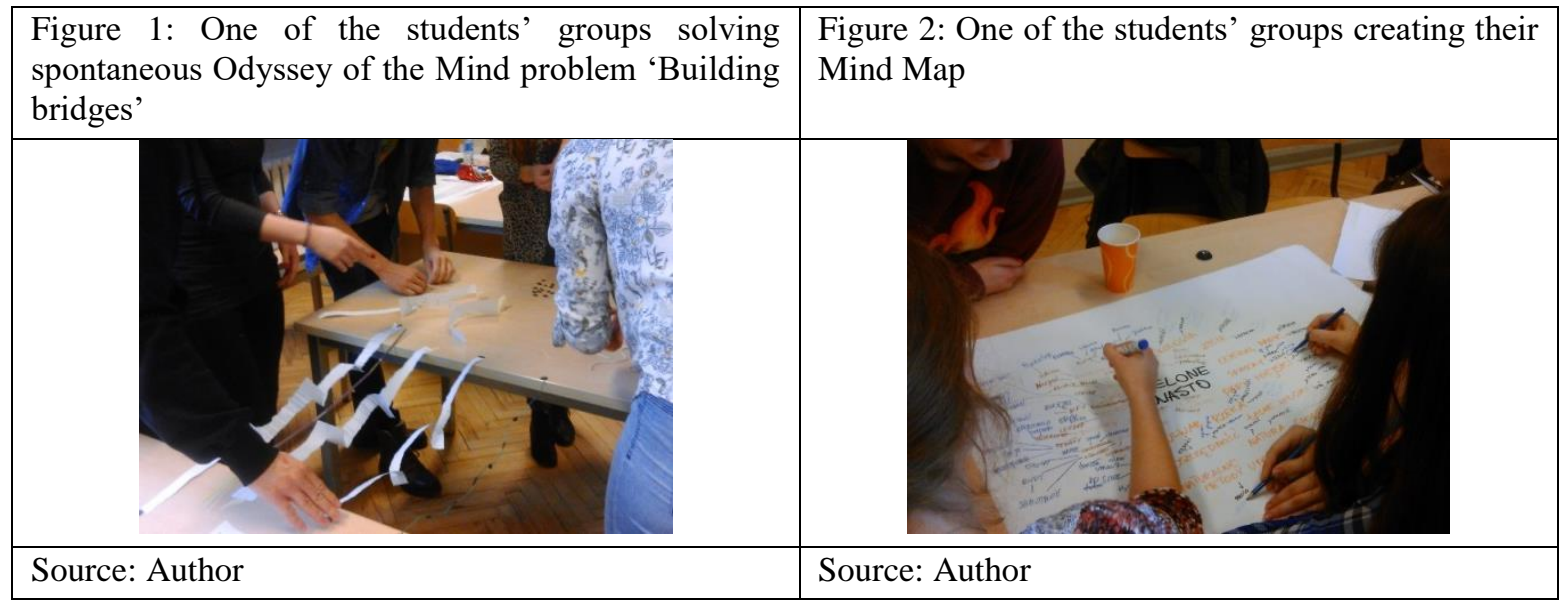

The 'Brainstorm' technique is the most popular one of all the creative problem-solving techniques, and is based on noting down all the answers and ideas that can be given to the chosen 'primary question.' It was invented by Alex Osborn in 1950s. Osborn (2009) indicates four main rules of the technique. The first of them says to leave away criticism, as at the first stage of the technique there is no such thing as a wrong answer. The second rule is that the wild ideas are much welcome. Next guideline highlights that the more ideas would be noted, the more possible it is to find a creative solution. The last one recommends to combine and improve answers and ideas using them as an inspiration for further actions. Consequently, a group of participants simply write down all the answers to that 'primary' question that come into their minds. That technique has also some modifications. Among them there is the 'Problem Reversal' technique, introduced by Charles Chic Thompson. According to Thompson (2007) starting the 'Brainstorm' with a reversed question may bring even more innovative and adequate results.

The next technique introduced during the course was the 'Superposition' technique. This one refers to the ability to connect distant things and phenomena. As Szmidt (2013) indicates it rests on connecting two or more objects to get a new one after proper modifications. Firstly, the user writes associations to some separate objects. Later, he draws individual associations to different objects and tries to connect them creating a new idea.

The last technique introduced during the course was the 'Superheroes' technique. It was created by Arthur B. Van Gundy and its main goal is to look at the given problem from the new perspective perspective of a superhero. At the beginning, the group of participants notes a problem to be solved and some names of superheroes. For each of the heroes the group writes down also the hero's superpowers and all the team members have to recognize all of the chosen characters. Then the team writes down how each of the superheroes would solve the given problem using his superpowers. Further on, as Lewandowska-Walter et al. (2015) describes those 'super' methods are converted or are the inspiration for inventing the 'real' methods of solving the problem.

Every part of the final students' presentation had to be done by a different technique. The ideas for the keynote-slogan for the city ought to be developed with the 'Mind Map' technique. An original architectural ideas for a Vertical Farm should be created using the 'Brainstorm' technique, while the concepts of an unusual building or a structure covered with a green roof had to be generated with the 'Problem Reversal' method. The 'Superheroes' technique should be used to prepare one defined social or spatial problem to be solved by citizens, whereas the 'Superposition' technique ought to be employed to create at least one other green or ecological solution to the design of 'The Fantastic Innovative Green City.'

Team-work activities

The crucial part of the course were the teamwork activities. They were very important in developing the ability of cooperation, which was and still is one of the most desired manpower ability at the labor market according to Lowden et al. (2011). During the whole course, the students worked in groups of 5 to 7 , creating their final project presentation together. The groups were chosen randomly during the first meeting. In the beginning, some students did not like that idea, but in the end, it appeared that the 
majority of them appreciated the possibility of working with teammates they would never choose by themselves. In that way, members of the groups had different backgrounds, attitudes, styles of working and experience, which as the result gave a greater variety of ideas. To strengthen the groups' identity, every team had to choose their name. The names were arbitrary, like for example Urban Heroes, Blue Forks or Fantastic Designers of Green Cities - as were the ones chosen during the course in 2015 and 2016. From the teachers' perspective, it was also important that every student had to work with many others because during the warm-up activities groups were chosen each time differently. But the final project was done by the 'basic' teams - the teams with names.

Final presentations

The results of the teams' work were presented during the $7^{\text {th }}$ meeting. Time of presentation was strictly limited to 10 minutes. The method of presentation was facultative. Even though some of the groups (5 out of 13) chose simple PowerPoint presentation, there were also many other interesting forms of final reports, such as drama, songs, films, and models. Figures 3 and 4 show some of the final presentations of the 2016's course.

\begin{tabular}{|l|l|}
\hline $\begin{array}{l}\text { Figure 3: Students' final presentation with a keynote } \\
\text { 'Clean air - pure thoughts' }\end{array}$ & $\begin{array}{l}\text { Figure 4: Students' final presentation in the form of } \\
\text { drama }\end{array}$ \\
\hline CZYSTE POWIETRZE - CZYSTE MYŚL!
\end{tabular}

\section{Evaluation criteria}

To ensure that the students obtain fair and differentiated marks at the end of the course, there were three main evaluation criteria. Each team got the scores for the group project presentation, but at the same time each individual got scores for the involvement and presence in the class.

Scores for the group's presentation

Each of the five obligatory elements of the presentation was scored for its originality and degree of refinement. Teams also got scores for the cohesion of all the elements of the project and originality of the presentation form. In every category, the group could get 10 points. Additionally, if all members of the group took part in the presentation, they could get ten extra points.

Involvement in the preparation process

As the educators were not able to observe each individual's involvement in the team's work, this part of the evaluation was made by the students themselves. Every student was asked to value the teamwork and involvement of the other members of the group, sharing among them 100 points in both categories. A large majority of the students divided points evenly. However, some of them differentiated the scores to reflect the actual individual involvement and thereby influenced the final marks of their teammates.

Attendance during the course

In this type of the course, which was focused on the teamwork activities during the class, it was not possible for the students to make progress without a presence in the class. Scores for attendance were an integral part of the mark. However, individual cases were discussed if needed.

\section{Students opinion in questionnaires}

At the end of each year of the course, students were asked to fill the questionnaires. After the courses in 2015 and 2016 there were 84 participants in total that filled the questionnaires. The questions referred to each part of the class. In the first part, there were questions testing the overall opinion of the course, checking whether it was interesting, attractive, and useful for the participant. In further 
three parts, the teachers asked the detailed questions to verify how students valued the blocks of the theoretical background lectures, the warm-up activities, and the problem-solving techniques. In the last part of the questionnaire, there was some space for comments. Below, the authors of the article are presenting detailed results of each part of the questionnaires, filled after the courses in years 2015 and 2016.

Students' overall opinion of the course

At the beginning of the questionnaires, the participants were asked if the course was interesting. The answer ranged from 1 to 5 points, which indicated the range from 'not interesting' to 'very interesting.' $42 \%$ of the students gave the course the highest score, $37 \%$ marked 4 as a score in this category. Seventeen students ticked middle score ( 3 points), only 1 person selected 2 points, while no one stated that the course was not interesting.

Next, the students were asked if the course was attractive. As it had happened earlier, they could give from 1 to 5 points as the answer. $39 \%$ of the respondents gave the course the highest score, and the same number of respondents chose 4 as a score in this category. Fifteen students $(18 \%$ of the surveyed) ticked the middle score, two students selected 2 points as an answer, and only 1 person judged course as not attractive at all.

The results of the students' evaluation concerning the usefulness of the course were slightly worse. $53 \%$ of the respondents gave the course the highest scores (5 or 4 points). Only one person judged the course as not useful at all, while ten students selected 2 points as their answer. Figure 5 shows that $33 \%$ of surveyed students ticked the middle score.

Students' opinions on the theoretical background lectures

Further part of the questionnaire had four questions concerning the theoretical background lectures. The first question in this part tested whether the gained knowledge at this part of the course would be used in future. The possible answers were: definitely yes, rather yes, maybe, rather not, definitely not. Most of the participants (65\%) chose 'rather yes' as an answer, fifteen students (18\%) seemed to be sure to use this knowledge in future, whereas 17\% selected 'maybe' as an answer. No one declared not to use the theoretical knowledge of 'green' solutions in urban areas in future. Then the students were asked to choose the 'green' solutions, which were presented during the lectures and which they liked most, and reckoned as the most effective and useful in future. $40 \%$ of the participants chose green roofs as the solution they preferred, and $43 \%$ of them pointed out that solution as the most probable to be used in future. On the other hand, the biggest group of students considered not only green roofs but also vertical farms as the most effective 'green' solution for urban space. This data are presented in Figure 6.

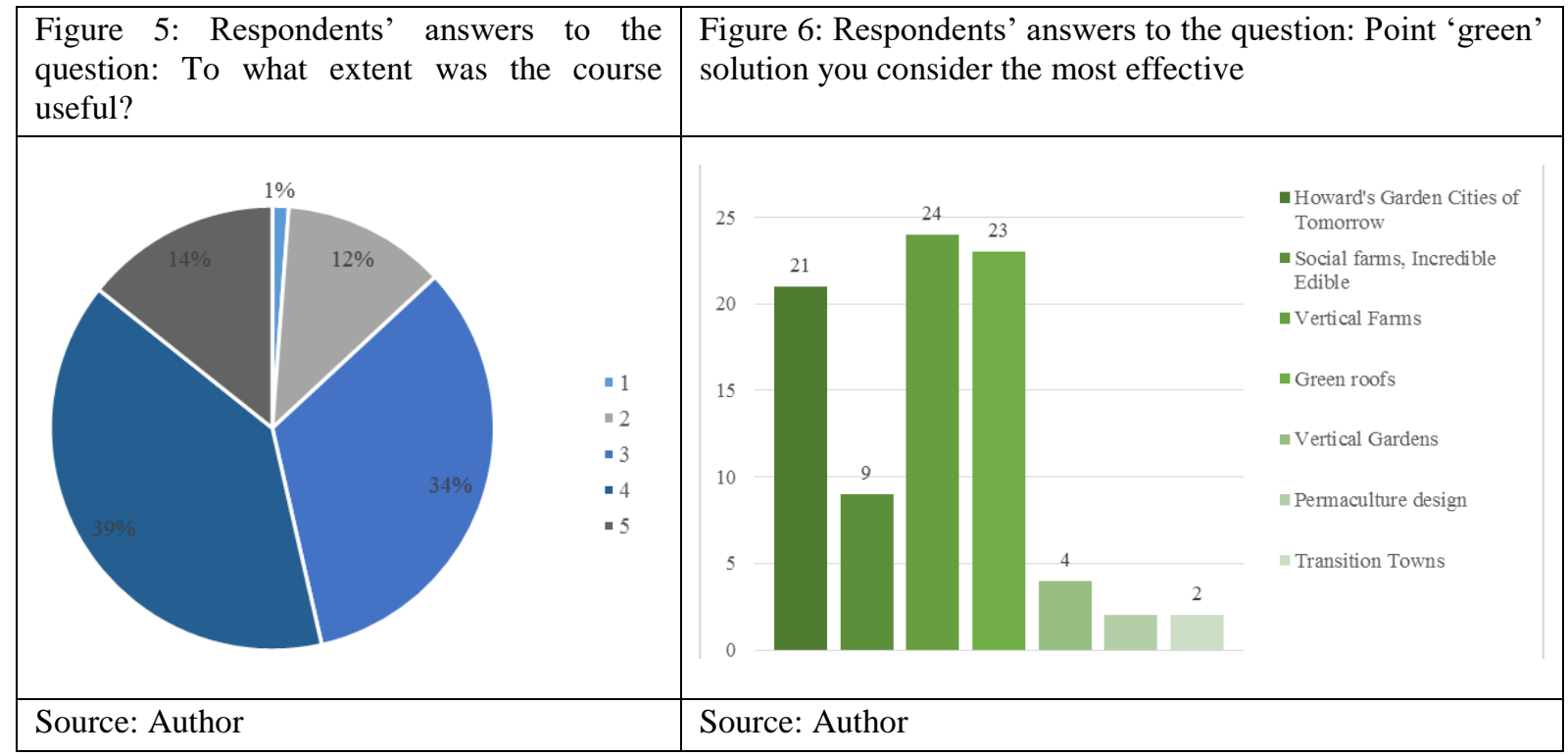


Students' opinions on the warm-up activities

Four questions concerning the warm-up activities were in the next part of the questionnaire. The first of these questions verified whether the tasks given during those activities would be useful in future. The possible answers were: definitely yes, rather yes, maybe, rather not, definitely not. The total of $28 \%$ of the participants declared that they 'rather' or 'definitely' would use that kind of activities in future, while $26 \%$ would 'rather not' or 'definitely not' use them. The most numerous group of students (39 persons) selected 'maybe' as the answer though. Then the students were asked to choose the warm-up activity that they liked most and considered the most efficient and useful in future. In that category, they pointed out the spontaneous task of the 'Odyssey of the Mind' as the most popular (28\%), the most efficient (29\%) and the most probable to be used in future (32\%) kind of warm-up activity. But as it can be seen in Figure 7, every warm-up activity presented during the course was declared to be used in future by at least ten students. What is more, only 8 out of 84 participants did not point out any of those tasks.

Students opinion on problem-solving techniques

Another part of the survey concerned the problem-solving techniques introduced during the course. The first question examined whether respondents would use them in future. The possible answers were: definitely yes, rather yes, maybe, rather not, definitely not. The great majority of respondents $(84 \%)$, declared 'rather yes' or 'maybe' as the answer, while eight students (10\%) were sure to use the techniques in future. As can be seen in Figure 8, only 6\% of participants answered 'rather not' or 'definitely not.'

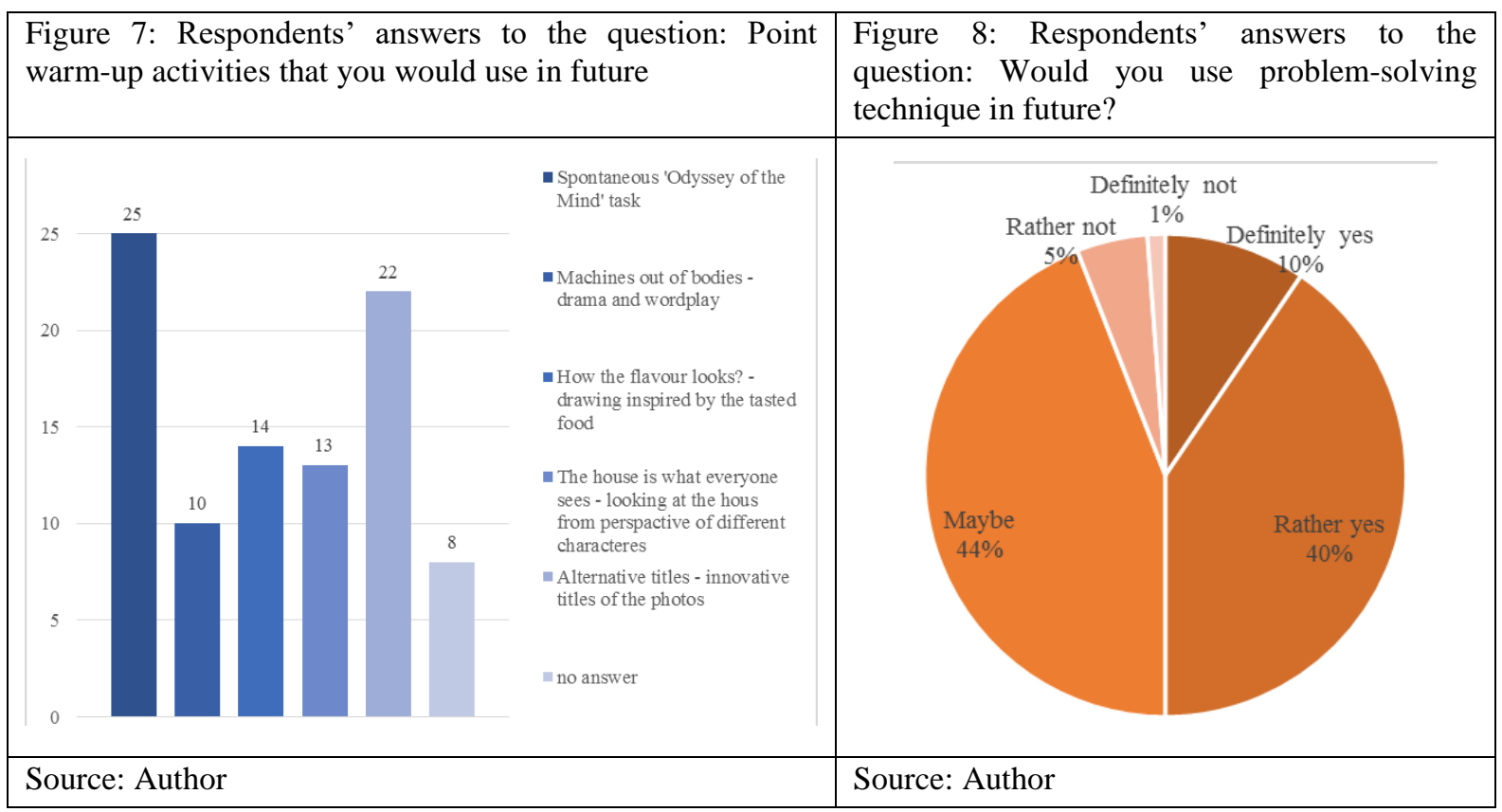

Then the students were asked to choose the technique that they liked most and considered to be most effective and useful in future. The technique which was pointed out was 'Brainstorm,' and it was chosen not only as the preferable technique but also as the most effective and useful in future by 28$31 \%$ of participants. Seven students regarded every of the introduced techniques as useful and only five people did not choose any of those tools.

\section{Students' suggestions and comments}

In the last part of the questionnaire, there was some space for the students to write their suggestions and comments. Only 26 out of 84 students decided to enter a few remarks. The majority of the comments were positive - saying that the course was very nice and suggested that there should be more hours devoted to it. However, 12 comments could be qualified as negative - four of them concerned the organization issues while eight claimed that the atmosphere of the course was too relaxed and that tasks were too easy. 
Results of the questionnaire

To summarize the above-mentioned results of the questionnaire, most of the participants considered the course to be interesting, attractive and useful. What is more, the great majority of the students declared to use the achieved theoretical knowledge about the 'green' solutions for the cities in future. Furthermore, the majority of the participants allow the possibility of using the warm-up activities as well as the problem-solving techniques in practice.

\section{Conclusion}

If we take into account the high quality and variety of students' projects presentations, as well as the good results of the students' questionnaires, the conclusion is that the goals of the course were achieved. In particular, the structure of the course appears to be correct, it was properly led and evaluated. Nevertheless, there is still room for improvement, regarding mainly the organization matters and the teachers would introduce them. But the fact is, that after the 2015 year edition, the teachers were asked to repeat the course in the years 2016 and 2017. It means that not only was it appreciated by the students but also by the staff and head of the Faculty of Architecture.

\section{References}

Buzan, T. (2005). The Ultimate Book of Mind Maps. London: Thorsons.

Creative Competitions Inc. (2017). Odyssey of the Mind - our story. Retrieved from Creative Competitions Inc. program: http://odysseyofthemind.com/p//our-story/

Kowalewska, J. (2016). Narzędzia treningu twórczości jako pomoc w kształceniu projektantów [Tools of creativity training as an aid in the education of designers]. In R. Idem (Ed.), Nauczanie w sztukach projektowych [Teaching the arts project] (pp. 41-51). Koszalin: Wydawnictwo Politechniki Koszalińskiej.

Lewandowska-Walter, A., Radziwiłowicz, W., \& Srokowski, Ł. (2015). Więcej niż Książeczka Trenera [More than a booklet Trainer]. Gdańsk: Odyssey of the Mind Polska.

Lowden, K., Hall, S., Elliot, D., \& Leiwn, J. (2011). Employers' perceptions of the employability skills of new graduates. London: Edge Foundation.

Odyssey of the Mind Polska. (2017). Odyseja Umystu - metoda [Odyssey of the Mind - method]. Retrieved from Odyssey of the Mind Polska - program Web: http://odyseja.org/o-odysei-umyslu/metoda-co-robimy/program-w-praktyce/

Osborn, A. (2009). Umlocking Your Creative Power, How to Use Your Imagination to Brighten Life, to Get Ahead. New York: Hamilton Books.

Szmidt, K. (2013). Trening Kreatywności Podręcznik dla Pedagogów, Psychologów i Trenerów [Creativity Training Manual for Teachers, Trainers and Psychologists]. Gliwice: Helion.

Thompson, C. (2007). What a Great Idea! 2.0 Unlocking Your Creativity in Business and in Life. New York: Sterling Publishing Co., Inc. 